\title{
Photovoltaics (PV) as an Eligible Measure in Residential PACE Programs: Benefits and Challenges
}

A significant barrier to investing in renewable energy and comprehensive energy efficiency improvements to homes across the country is the initial capital cost. Property Assessed Clean Energy (PACE) financing is one of several new financial models broadening access to clean energy by addressing this upfront cost issue.

Recently, the White House cited PACE programs as an important element of its "Recovery through Retrofit" plan. ${ }^{1}$ The residential PACE model ${ }^{2}$ involves the creation of a special clean energy financing district that homeowners elect to opt into. Once opted in, the local government (usually at the city or county level) finances the upfront investment of the renewable energy installation and/or energy efficiency improvements. A special lien is attached to the property and the assessment is paid back as a line item on the property tax bill. ${ }^{3}$

As of January 2010, 16 states have passed legislation in the last 18 months to allow their local governments to create PACE programs, 2 already have the authority to set up PACE programs, and 14 additional states are actively developing enabling legislation.

The majority of the PACE programs in the market today include PV as an eligible measure. ${ }^{4}$ PV appeals to homeowners as a way to reduce utility bills, self-generate sustainable power, increase energy independence and to demonstrate a commitment to the environment. If substantial state incentives for PV exist, PV projects can be economic under PACE, especially when partnered with good net metering policies. ${ }^{5}$ At the same time, $\mathrm{PV}$ is expensive relative to

\footnotetext{
The October 2009 report "Recovery Through Retrofit" produced by Vice President Joe Biden's Middle Class Task Force is available here: www.whitehouse.gov/assets/documents/Recovery_Through_Retrofit_Final_Report.pdf

2 In many cases, PACE assessments can be placed on both residential and commercial properties. In this fact sheet, we focus on residential properties because that is where there is the most experience to date.

${ }^{3}$ For more detailed information on PACE financing programs, please visit: www.eecbg.energy.gov/solutioncenter/financialproducts/PACE.html

${ }^{4}$ Babylon, New York, is the one exception-although they will consider it on a case-by-case basis.

${ }^{5}$ Net metering refers to the ability to sell excess electricity back to the local utility. For PV, good net metering rates imply that the homeowner can sell his or her excess electricity back at retail rates.
}

other eligible measures with a return on investment horizon that might exceed program targets. It is within this context that this fact sheet reviews the benefits and potential challenges of including PV in PACE programs. ${ }^{6}$

\section{Benefits}

\section{Consumer demand for PACE-financed PV systems}

The existing pilot programs demonstrate that homeowners want to use PACE financing to install PV systems. As examples, Palm Desert, California, has reserved half of the $\$ 6$ million in currently available funding for solar projects. ${ }^{7}$ Of the 612 projects financed by Boulder County, Colorado, in its first two residential financing rounds in 2009, PV was the most popular single project followed by windows and insulation. ${ }^{8}$ In Sonoma County, California, approximately half of the 700 applications received in 2009 were for solar projects. ${ }^{9}$

One can argue that a PACE program is highly suited to finance PV systems. The upfront investment for PV is significant and the homeowner may not have access to a home equity loan or other sources of financing. The long repayment terms associated with PACE programs spread out the cost of a PV system over time to better match the benefits of lower electricity bills over this same time period. Finally, the ability to transfer the lien to the subsequent homeowner reduces the investment risk should the homeowner sell the property. In other words, PACE programs appear to be designed with PV installations in mind.

\section{Encourage energy efficiency investments}

It is well established that investing in energy efficiency is the smartest use of a homeowner's first energy dollar. The upfront investment is modest compared with what's required

\footnotetext{
${ }^{6}$ This fact sheet is focused on the PACE-financed PV projects in particular, although many of the same issues may result from large energy efficiency projects that lead to a large PACE lien.

7 City of Palm Desert, CA's Energy Independence Program. www.cityofpalmdesert.org/Index.aspx?page $=484$

8 "Financing Program Support for ARRA Recipients." PACE Webinar November 2009. U.S. Department of Energy. Energy Efficiency and Renewable Energy. www.eecbg.energy.gov/Downloads/EECBG_PACE_ Webinar_111709.pdf

9 Ibid.
} 


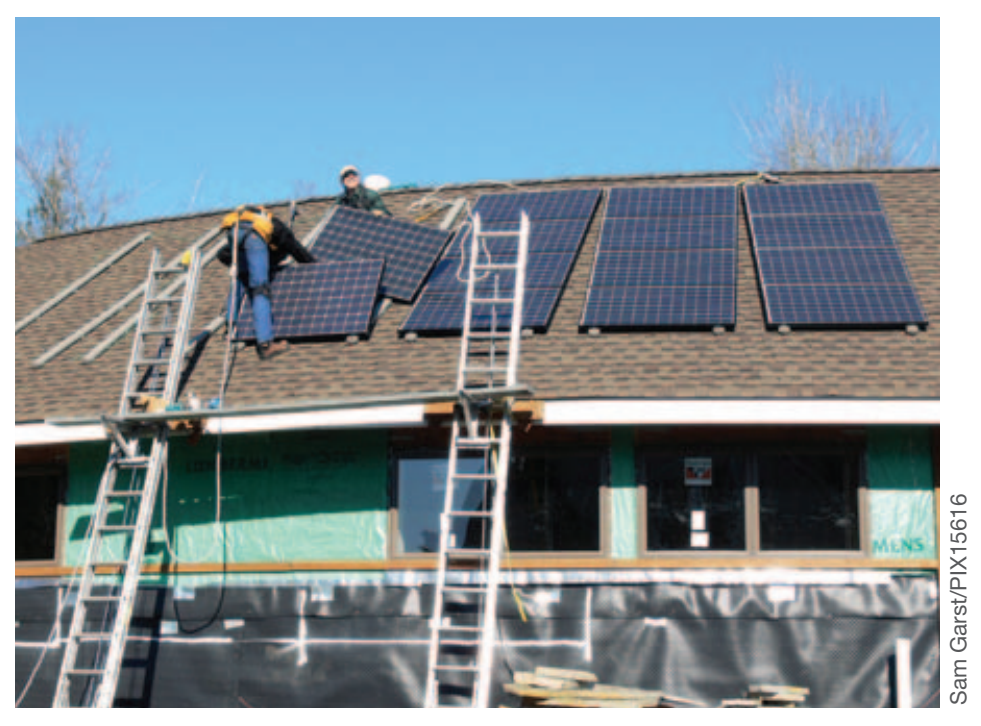

for a PV system. The return on investment can often be realized within a few years or less. In addition, energy efficient homes may be increasingly more attractive in the market as potential buyers begin to pay more attention to the operating costs of a house. In fact, installing a PV system on an inefficient home is not recommended. By investing in energy efficiency first, a smaller PV system can be installed to offset the same percentage of a home's electricity consumption, or conversely, the same system will now offset a greater percentage of electricity consumption.

However, despite what would seem to be a compelling argument to make energy efficiency investments before installing a PV system, homeowners are often interested in PV as the first project. Most PACE programs will either require a certain level of energy efficiency before PACE financing can be used for PV or at least, strongly encourage it. Regardless, it is clear that PV can be used as the motivator for energy efficiency. By conditioning access to PACE financing for PV on a certain level of energy efficiency, the homeowner can be guided into carrying out more integrated projects.

\section{Ability to create program scale}

The upside of PV being one of the most expensive eligible PACE measures is that it may allow for programs to be larger, in dollar terms. One residential PV installation might be the equivalent of several separate energy efficiency investments. Large programs will attract a broader array of financial investors. For the most part, major investors, such as banks and insurance companies, are not interested in small investments, particularly in niche products. Small markets do not create the necessary liquidity to buy and sell financial instruments in an efficient manner. In addition, it can be costly for a large institution to staff up to prepare for a new project or product. Without significant revenue and profit potential, it is not a good use of internal resources. Therefore, if scale is necessary to create a national PACE market with a vibrant secondary market-and scale on the order of hundreds of millions of dollars-including PV in such programs gets to this level much faster. ${ }^{10}$

\section{Quality control and measuring effectiveness}

With potential fraud and poor workmanship a concern, program administrators are focused on the quality of the work that will be done under PACE programs. No one wants to burden a homeowner with a special tax assessment for a project that does not meet cash flow expectations. So while admittedly more expensive to install, ensuring quality control and measuring savings for PV may indeed be easier than for many energy efficiency investments.

At the most basic level, it is quite straightforward to see if a PV installation has been done at a home. Determining whether or not insulation has been injected into the walls of a home, for example, is more difficult. As far as measuring performance and energy savings, there are a number of software monitoring programs that allow the homeowner to see in real time how many kilowatt-hours are being produced by the PV system. ${ }^{11}$ Calculating the natural gas savings from insulation and new windows is less straightforward. This ability to measure electricity production and calculate energy savings is an advantage that PV has over many energy efficiency investments, which may not lend themselves as easily to similar performance measurements.

\section{Potential Challenges}

\section{Meeting the Savings to Investment principle}

The federal government sees the value of PACE financing as a way to drive both energy conservation and job creation. The White House has developed a series of guiding principles for PACE with the goal of incorporating certain safeguards for both homeowners and mortgage lenders. ${ }^{12}$ The first principle is as follows:

Savings to Investment Ratio. As has long been the case for DOE's single-family weatherization program, the "savings to investment ratio" for PACE program assessments should be greater than one. This "pay for itself" principle means that the expected average monthly utility savings to homeowners should be greater than the expected monthly increase in tax assessments due to the PACE energy efficiency or renewable energy improvements. Improvements should be made where there is a positive net present value,

\footnotetext{
10 This statement ignores PACE programs for commercial entities. Energy efficiency investments at a factory or warehouse can be quite significant and certainly can exceed the cost of a residential PV system. Nonetheless, the argument still holds because a PV installation at a commercial entity will likely be as large if not larger than even the energy efficiency investments.

11 This actual production can be compared with what is a certain level of guaranteed solar panel production by the manufacturer and often the installer for an extended period of time.

12 Policy Framework for PACE Programs. October 2009. www. whitehouse. gov/assets/documents/PACE_Principles.pdf
} 
so that expected total utility bill savings are estimated to be greater than expected total costs (principal plus interest). In some instances, tax credits or other subsidies are available to support investments. If so, then the present value of the expected savings to consumers should be greater than the present value of the increase in assessments once those subsidies are included.

Depending on the circumstances of each PV installation, whether or not it will "pay for itself" on a monthly basis will vary tremendously. There are a myriad of solar incentive programs across the country offering a wide range of financial support for PV-only a few of which are currently driving substantial PV development. At the same time, the cost of electricity varies significantly-from less than $\$ 0.10$ per kilowatt-hour ( $\mathrm{kWh}$ ) in many states to more than $\$ 0.15 / \mathrm{kWh}$ in California and the Northeast. ${ }^{13}$ Solar resources also vary as well. Solar production in Arizona will exceed that of Minnesota for a given system. So while in some cases a PACE-financed PV installation will have positive cash flow and positive net present value from the start (given the right combination of good resources, high electricity prices and generous incentives), in other cases it will not. Assumptions of future increases in retail electricity prices are critical to this analysis and this is difficult to estimate accurately. Therefore, if PACE programs are to adhere to these core principles, PV may not meet the savings to investment principle in all jurisdictions.

\section{Transferring PV PACE assessments upon home sale}

One of the pillars of PACE financing is that the property lien transfers to the new owner when a home is sold. This removes a disincentive for homeowners to make those significant investments in their homes that have long payback periods. As noted earlier, this is advantageous for PV given that the investment, on average, will be among the largest projects financed in a PACE program. While occupying the home, the homeowner both pays for and benefits from the PV system, regardless of whether it is the original owner who installed the system, or subsequent ones. However, it is not known whether or not a prospective buyer will take into account the amount of the outstanding lien when negotiating the final purchase price of a home.

Because current PACE programs are still relatively new, there is not a lot of data to illustrate how an outstanding lien may influence the selling price of a home or if the lien will need to be prepaid as a condition of the sale. Even though the value of a home may be enhanced by having a PV system, ${ }^{14}$ it is possible that both mortgage lenders and prospective home

\footnotetext{
13 Average Retail Price of Electricity to Ultimate Customers by End-Use Sector, by State. Oct. 2009. Electric Power Monthly. U.S. Energy Information Administration. www.eia.doe.gov/cneaf/electricity/epm/table5_6_b.html

14 While there is some evidence that indicates that homes with PV sell faster and at a higher price than those without, a lot more analysis is required in this area to make any definitive statements.
}

buyers will be influenced by the existence of a special lien on the house-a lien that can easily exceed $\$ 25,000$ if it is a recently financed PV system. ${ }^{15}$

If the home seller has to adjust his or her selling price downward to account for the outstanding lien (or repay the lien), one of the primary benefits of PACE financing is jeopardized and the return on investment for the original participant in the PACE program may be much less than expected. In Boulder County's PACE program, to date, one home with a PACE PV lien has sold. In this instance, the lien was paid off by the seller as a condition of the sale. ${ }^{16}$ The fact that the original homeowner got the full benefit from the residential investment tax credit was apparently a factor in the negotiation process that resulted in the lien being repaid (Boulder County does not net out the investment tax credit from the lien). ${ }^{17}$ While this is only a single example, it does illustrate the potential for such liens to be an issue in the future.

\section{Impact of mortgage refinancing on the PACE lien for PV}

In a scenario in which the mortgage for a home that carries a PACE lien is refinanced, it is possible that the bank will require that the PACE lien is paid off or rolled into the new mortgage. This would reduce the amount of outstanding claims that are senior to the mortgage should a homeowner default. Given that PACE lien seniority ${ }^{18}$ is already an issue within the mortgage banking community, banks may capitalize on the refinancing transaction as a way to eliminate the lien. Repaying the lien and rolling it into a new mortgage severs the connection with the property tax assessment process and as a result, the obligation is no longer transferable to the next homeowner upon an event of sale.

As was noted previously, there are very few sales data available for homes with PACE loans. However, in Palm Desert, there are at least two cases of homeowners with PACE liens who refinanced their mortgages. ${ }^{19}$ In both cases, the PACE liens were paid off as part of the transaction. It is unclear whether the liens were rolled into the new mortgages or if the homeowners had to repay them prior to qualifying for the refinancing.

\footnotetext{
${ }^{15}$ Maximum loan amounts vary across programs. As examples, Boulder County, Colorado, has a limit of the lesser of $20 \%$ of the statutory value of the property or $\$ 50,000$ in its open program. Berkeley, California, set a maximum of $\$ 37,500$ for PV projects in its pilot program: Palm Desert, California, has a maximum of $\$ 100,000$ with special approval required for projects exceeding $\$ 60,000$.

${ }^{16}$ February 2010 e-mail communications with Boulder County PACE program administrators.

17 lbid.

18 "Senior" referring to the order in which loans are repaid in the event of default.

19 February 2010 phone conversation between Benjamin Druyon, the Palm Desert program administrator and Lawrence Berkeley National Laboratory's Mark Zimring.
} 


\section{Federal support for PACE and the impact on other PV business models}

PACE financing is receiving significant attention at the federal level given its potential to generate significant energy savings across the country while creating jobs. As a result, some level of formal federal support for PACE programs would not be surprising. However, there are other financial models in the residential PV marketplace in addition to the home equity loan and which also address the upfront cost barrier. These include the solar lease and the residential power purchase agreement (PPA).

Under a solar lease, the homeowner leases the PV system for an extended period of time; the electricity bill savings are expected to offset the lease payments. Under a residential PPA, the homeowner purchases the electricity produced by the roof-top PV system as it is generated. In both models, third-party ownership of the system allows commercial investment tax credits to be monetized for the benefit the homeowner. ${ }^{20}$ In a PACE program, the homeowner has the option of taking the $30 \%$ residential investment tax credit.

The solar lease, and to a lesser degree, the residential PPA, are experiencing increasing demand in various residential markets across the country. To the degree that PACE programs were to benefit from direct federal assistance ${ }^{21}$ either in the form of loan guarantees or secondary market purchases-and these PACE programs included PV as an eligible measure, it could be argued that the solar lease and the residential PPA would face a competitive disadvantage given PACE program access to subsidized capital. ${ }^{22}$ Given that these competing models are also attracting customers and expanding the residential PV market, the implications of federal support for PACE programs should be considered.

\section{Summary}

This fact sheet does not recommend whether or not PV should be included in PACE programs. However, given the momentum behind the PACE model across the country (particularly for PV), it is important to look at a variety of issues that have not yet been explored. It is for policy makers to determine if residential PACE programs should include PV as an eligible measure. As illustrated previously, there are certain benefits for inclusion but challenges exist as well. Nonetheless, these issues should be debated while PACE programs are still in their infancy.

\footnotetext{
20 The homeowner benefits in the form of a lower monthly lease payment or a lower price per kilowatt-hour in the PPA as a result of the system owner benefitting from the tax credits and accelerated depreciation.

21 Not intended to imply that federal support is likely or expected, but rather to point out a possible impact if it were to happen.

22 Of course, $\mathrm{PV}$ is already federally subsidized via the tax code so the issue is more the degree of subsidy rather than subsidies themselves.
}

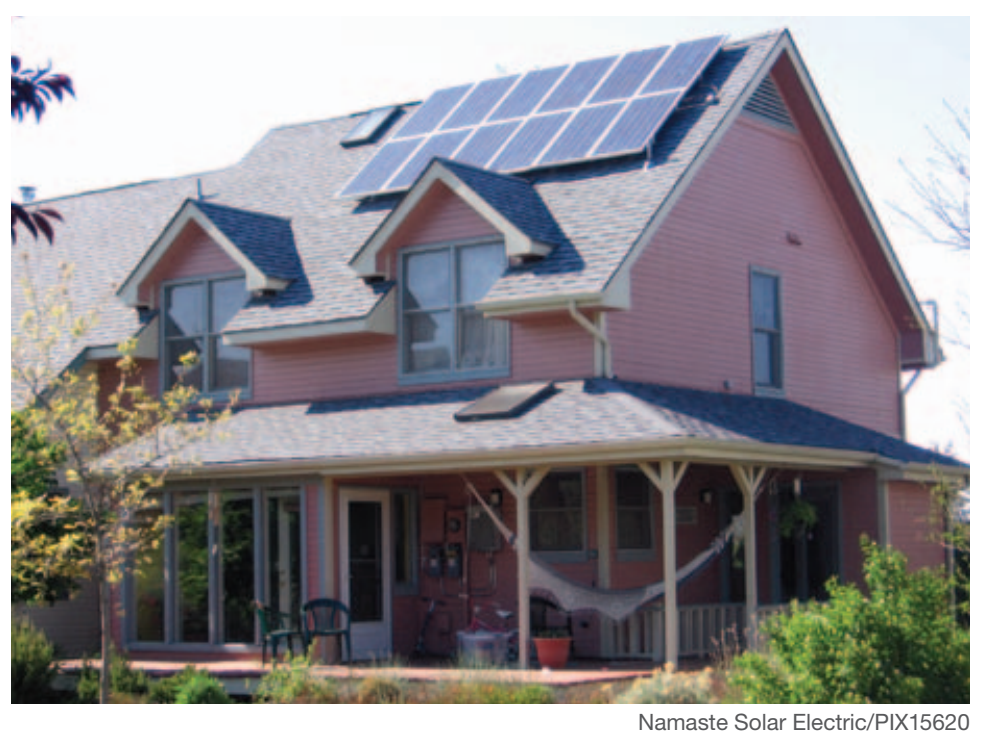

\section{Contacts}

This factsheet was written by Jason Coughlin of NREL. For more information, contact Jason Coughlin at Jason.Coughlin@nrel.gov.

This report was made possible through funding from the U.S. Department of Energy's Solar America Cities program. To learn more, please visit www.solaramericacities.energy.gov

\section{ONREL \\ NATIONAL RENEWABLE ENERGY LABORATORY}

National Renewable Energy Laboratory

1617 Cole Boulevard, Golden, Colorado 80401

303-275-3000 • www.nrel.gov

NREL is a national laboratory of the U.S. Department of Energy

Office of Energy Efficiency and Renewable Energy

Operated by the Alliance for Sustainable Energy, LLC

NREL/BR-7A2-47845 • June 2010

Printed with a renewable-source ink on paper containing at least $50 \%$ wastepaper, including $10 \%$ post consumer waste. 